\title{
Caracterização histopatológica e imuno-histoquímica de neoplasmas mesenquimais da genitália em 43 cadelas ${ }^{1}$
}

\author{
Suyene O. de Souza ${ }^{2}$, Tatiane T.N. Watanabe ${ }^{2}$, Renata A. Casagrande ${ }^{2}$, \\ Angelica T.B. Wouters ${ }^{2 *}$, Flademir Wouters ${ }^{2}$ e David Driemeier ${ }^{2}$
}

\begin{abstract}
Souza S.O., Watanabe T.T.N., Casagrande R.A., Wouters A.T.B., Wouters F. \& Driemeier D. 2012. [Histopathological and immunohistochemical characterization of mesenchymal neoplasms of the genitalia in 43 bitches.] Caracterização histopatológica e imuno-histoquímica de neoplasmas mesenquimais da genitália em 43 cadelas. Pesquisa Veterinária Brasileira 32(12):1313-1318. Setor de Patologia Veterinária, Faculdade de Veterinária, Universidade Federal do Rio Grande do Sul, Av. Bento Gonçalves 9090, Porto Alegre, RS 91540-000, Brazil. E-mail: angelicawouters@yahoo.com.br

The biopsies archives from SPV-UFRGS (2000-2010) were retrieved, and cases of mesenchymal neoplasms of genitalia (uterus, cervix, vagina, and vulva) of 43 bitches were revised. Also Masson's trichrome staining (MT) and immunohistochemical characterization were evaluated. The main breeds affected were Cocker, Poodle and German Shepherd, but the greatest number of cases were observed in mixed breed dogs. The average age of the bitches was 10.6 years (3-10 years of age). The anatomical locations of the neoplasms were vagina $(44.2 \%)$, uterus $(27.9 \%)$, vulva $(23.3 \%)$ and cervix $(4.6 \%)$. Histologically, $46.5 \%$ were classified as leiomyoma, $41.9 \%$ as fibroleiomyoma, $7.0 \%$ as fibroma, and $4.6 \%$ as leiomyosarcoma. In MT staining, the fibroma had all neoplastic cells stained blue (collagen), the leiomyomas and leiomyosarcomas had less than $50 \%$ of collagen among the muscle neoplastic cells, and the fibroleiomyomas had more than $50 \%$ of collagen. Positive immunostaining for vimentin and absence for desmin was observed in fibroma. Leiomyomas were positive for vimentin in more than $50 \%$ of the cells, and for desmin (in $75 \%$ of the cases in more than $50 \%$ of the cells, and in $25 \%$ less than $50 \%$ ). Regarding leiomyossarcomas, one case had immunostaining for vimentin and absence for desmin, and the opposite occurred in the other. Fibroleiomyomas were positive for vimentin in $94.4 \%$ (in more than $50 \%$ of the cells) and for desmin in $77.8 \%$ (64.3\% in less than $50 \%$ of the cells, and $35.7 \%$ in more than $50 \%$ of the cells).
\end{abstract}

INDEX TERMS: Neoplasias, mesenchymal neoplasms, genital system, immunohistochemistry, dogs.

RESUMO.- Os arquivos de biópsia do período de 2000 a 2010 do SPV-UFRGS foram revisados e levantados os casos de neoplasias mesenquimais de genitália (útero, cérvix, vagina e vulva) de cadelas. Realizou-se estudo retrospectivo de 43 casos, incluindo caracterização histológica, coloração tricrômico de Masson (TM) e imuno-histoquímica (IHQ). As principais raças acometidas foram Cocker, Poodle e Pastor Alemão, porém o maior número de casos foi observado

\footnotetext{
${ }^{1}$ Recebido em 19 de julho de 2012.

Aceito para publicação em 21 de setembro de 2012.

${ }^{2}$ Departamento de Patologia Clínica Veterinária, Faculdade de Veterinária (FAVET), Universidade Federal do Rio Grande do Sul (UFRGS), Av. Bento Gonçalves 9090, Porto Alegre, RS 95320-000, Brasil. *Autor para correspondência: angelicawouters@yahoo.com.br
}

em cães sem raça definida (SRD). A idade média dessas cadelas foi de 10,6 anos (variação de 3 a 10 anos). Quanto à localização dos tumores, 44,2\% estavam na vagina, $27,9 \%$ no útero, $23,3 \%$ na vulva e $4,6 \%$ na cérvix. Histologicamente, $46,5 \%$ eram leiomioma, $41,9 \%$ fibroleiomioma, $7,0 \%$ fibroma e 4,6\% leiomiossarcoma. Na coloração de TM, os fibromas apresentaram todas as células neoplásicas coradas em azul (colágeno), os leiomiomas e os leiomiossarcomas apresentaram menos de $50 \%$ de colágeno em meio às células neoplásicas musculares e os fibroleiomiomas mais de $50 \%$. Na IHQ os fibromas apresentaram marcação positiva para vimentina e negativa para desmina. Todos os leiomiomas eram positivos para vimentina (em mais de $50 \%$ células) e para desmina ( $75 \%$ dos casos em mais de $50 \%$ das células e $25 \%$ em menos de $50 \%$ ). Em um dos casos 
de leiomiossarcoma houve imunomarcação para vimentina e ausente para desmina e, no outro, ocorreu o oposto. Os fibroleiomiomas apresentaram marcação para vimentina em $94,4 \%$ (em mais de $50 \%$ células) e para desmina em $77,8 \%(64,3 \%$ em menos de $50 \%$ das células e $35,7 \%$ em mais de $50 \%$ ).

TERMOS DE INDEXAÇÃO: Neoplasias, neoplasmas mesenquimais, sistema genital, imuno-histoquímica, caninos.

\section{INTRODUÇÃO}

Os neoplasmas de genitália (útero, cérvix, vagina e vulva) mais comuns em cadelas são os de origem mesenquimal. Dentre esses, o mais frequente é o leiomioma, seguido pelo fibroma, o fibroleiomioma e o leiomiossarcoma (Kennedy et al. 1998, MacLachlan \& Kennedy 2002). Esses neoplasmas podem ser constituídos por massas únicas ou múltiplas e geralmente acometem fêmeas de meia idade ou mais velhas. Os hormônios sexuais podem influenciar seu aparecimento e frequentemente estão associados a cistos foliculares ovarianos, tumores secretores de estrógenos, hiperplasia endometrial, hiperplasia e neoplasia mamária (Schlafer \& Miller 2007). Esses tumores podem interferir na função reprodutiva, obstruir a uretra e o intestino (Cooper \& Valentine 2002).

Quanto à diferenciação entre leiomioma, fibroleiomioma e fibroma a literatura muitas vezes é controversa. 0 fibroma é constituído exclusivamente por tecido conjuntivo e o leiomioma por células musculares lisas bem diferenciadas com quantidade variável de estroma colagenoso. No entanto, para muitos patologistas, quando há tecido conjuntivo abundante em meio à proliferação neoplásica benigna de músculo liso, o neoplasma denomina-se fibroleiomioma (Cooper \& Valentine 2002).

A diferenciação histológica entre músculo liso e colágeno muitas vezes é difícil na coloração rotineira de hematoxilina e eosina. A utilização de coloração especial e imuno-histoquímica com marcadores específicos pode auxiliar na identificação mais precisa do tipo celular (Andreasen \& Mahaffey 1987).

O objetivo deste trabalho foi caracterizar os neoplasmas mesenquimais oriundos da genitália de cadelas provindas de biópsias do arquivo do Setor de Patologia Veterinária (SPV) da Faculdade de Veterinária da Universidade Federal do Rio Grande do Sul (FAVET/UFRGS), no período de 2000 a 2010, por meio dos achados histopatológicos, histoquímicos e imuno-histoquímicos.

\section{MATERIAL E MÉTODOS}

Os arquivos de exames anatomopatológicos do período de janeiro de 2000 a dezembro de 2010 do SPV-FAVET/UFRGS foram revisados e as biópsias com diagnóstico de fibroma, leiomioma, fibroleiomioma e leiomiossarcoma da genitália de cadelas (útero, cérvix, vagina e vulva) foram selecionadas. As características dos animais acometidos e a localização foram registradas e analisadas. Realizaram-se a busca dos blocos de parafina, os cortes em $3 \mu \mathrm{m}$, coloração pelo método de hematoxilina e eosina (HE) e estudo morfológico dos casos. 0 índice de mitoses nos neoplasmas foi avaliado através da contagem das figuras de mitoses em 10 campos microscópicos (objetiva 40x) e realização da média aritmética. Cortes foram também submetidos à coloração especial de tricrômico de Masson (TM), que cora em azul o colágeno e em vermelho as células musculares.

As amostras foram submetidas à técnica de IHQ pelo método estreptavidina-biotina-peroxidase. 0 bloqueio da atividade da peroxidase endógena foi realizado com a incubação dos cortes dos tecidos em solução a $10 \%$ de peróxido de hidrogênio (30 vol.) em metanol durante 10 minutos. Para a recuperação antigênica utilizou-se tampão citrato $\mathrm{pH} 6$ por três minutos a $125^{\circ} \mathrm{C}$ (vimentina), tampão Tris-EDTA, pH 9, dois ciclos de cinco minutos cada em microondas com potência de 750W (desmina). Os anticorpos monoclonais anti-vimentina (clone V9, 18-0052, Zymed) e anti-desmina (clone D33, DakoCytomation) foram diluídos em 1:200 e 1:300, respectivamente, em solução salina tamponada com fosfato (PBS). As lâminas foram incubadas em câmara úmida por 14-16 horas (overnight) a $4^{\circ} \mathrm{C}$ com o anticorpo primário e, após esta etapa, os cortes foram incubados com anticorpo secundário biotinilado seguido da estreptavidina-peroxidase (kit LSAB-HRP, K0690, DakoCytomation) por 20 minutos cada etapa. Como cromógeno utilizou-se o 3,3' diaminobenzidina (DAB-K3468, DakoCytomation) para a revelação e contracoloração com hematoxilina de Harris. Como controle positivo utilizou-se um corte histológico de coração de canino para desmina e um corte de fibrossarcoma de felino para a vimentina.

Para as diferentes intensidades de marcação foram atribuídos os graus de (-) ausência de marcação; $(+)$ intensidade discreta; $(++)$ intensidade moderada e $(+++)$ intensidade acentuada. Com relação à área positivamente marcada do neoplasma pela IHQ, ela foi dividida em dois subgrupos; com menos de $50 \%$ de células positivas $(<50 \%)$ e mais de $50 \%$ de células positivas (>50\%).

De acordo com os resultados da coloração de TM e o perfil imuno-histoquímico, os neoplasmas foram reclassificados em: fibroma, quando o neoplasma era constituído exclusivamente por fibroblastos/fibrócitos neoplásicos bem diferenciados com abundante estroma colagenizado; leiomioma, quando era formado por células musculares lisas benignas e com menos de $50 \%$ de estroma colagenizado; fibroleiomioma, quando de neoplasma constituído por células musculares lisas benignas e com mais de $50 \%$ de estroma colagenizado e leiomiossarcoma, quando era formado por células musculares lisas malignas com grau variável de tecido conjuntivo fibroso.

\section{RESULTADOS}

\section{Caracterização dos casos}

Durante o período de janeiro de 2000 a dezembro 2010 foram realizados no SPV-Favet/UFRGS 43 diagnósticos de fibroma, leiomioma, fibroleiomioma ou leiomiossarcoma na genitália de cadelas.

As características das cadelas acometidas por esses neoplasmas são apresentadas no Quadro 1. Aproximadamente $37 \%(16 / 43)$ dos animais não tinham raça definida (SRD), 14\% (6/43) eram Cocker, 9,3\% (4/43) Poodle e 7\% (3/43) Pastor Alemão. As raças Yorkshire, Rottweiler, Dobermann e Terrier Brasileiro perfizeram 4,6\% (2/43) cada; Akita, Dogue Alemão, Fila Brasileiro, Labrador, Schnauzer 2,3\% (1/43) cada e, em um caso, não havia especificação da raça na ficha clínica. A idade média das cadelas foi de 10 anos e 6 meses, com variação de 3 a 10 anos, sendo que, na ficha de três animais, não havia essa informação. Em nenhum desses casos havia informação sobre castração na ficha clínica.

Quanto à localização dos neoplasmas, 44,2\% (19/43) estavam na vagina, $27,9 \%(12 / 43)$ no útero, $23,3 \%$ (10/43) 
na vulva e 4,6\% (2/43) na cérvix. Além desses neoplasmas, em $14 \%$ das cadelas observou-se hiperplasia endometrial cística (Casos 10, 16, 31, 33, 38 e 42), em 9,3\% piometra (Casos 30, 31, 35 e 36) e, em 7\%, cistos ovarianos (Casos 17,23 e 30 ).

\section{Caracterização histológica}

$\mathrm{Na}$ avaliação histológica dos 43 casos, 46,5\% (20/43) eram leiomiomas; $41,9 \%$ (18/43) fibroleiomiomas; 7,0\% (3/43) fibromas e 4,6\% (2/43) leiomiossarcomas (Quadro 1). Nesses neoplasmas havia proliferação predominante de células alongadas e, em um dos casos de leiomiossarcoma, proliferação mista de células alongadas e ovoides. Quanto ao arranjo celular, todos os leiomiomas, $66,7 \%(12 / 18)$ dos fibroleiomiomas e $50 \%(1 / 2)$ dos leiomiossarcomas apre-

Quadro 1. Caracterização dos caninos acometidos por neoplasma mesenquimal da genitália, incluindo localização, classificação do neoplasma e contagem mitótica

\begin{tabular}{|c|c|c|c|c|c|}
\hline Caso & $\begin{array}{l}\text { Idade } \\
\text { (anos) }\end{array}$ & Raça & Localização & Diagnóstico & $\begin{array}{c}\text { Número de } \\
\text { mitoses }^{\mathrm{a}}\end{array}$ \\
\hline 1 & 9 & Akita & Vagina & Fibroleiomioma & 2 \\
\hline 2 & 3 & Terrier Brasileiro & Útero & Fibroleiomioma & 1 \\
\hline 3 & 14 & Pastor Alemão & Vagina & Leiomioma & 0 \\
\hline 4 & 8 & Pastor Alemão & Vagina & Leiomioma & 0 \\
\hline 5 & 12 & $\mathrm{NI}^{\mathrm{b}}$ & Vagina & Fibroma & 0 \\
\hline 6 & 6 & Yorkshire & Vulva & Leiomioma & 0 \\
\hline 7 & 9 & Poodle & Vagina & Fibroleiomioma & 0 \\
\hline 8 & 10 & Cocker & Vagina & Fibroleiomioma & 0 \\
\hline 9 & 15 & Terrier Brasileiro & Vagina & Leiomioma & 1 \\
\hline 10 & 11 & Rottweiler & Útero & Fibroleiomioma & 0 \\
\hline 11 & 10 & Dog Alemão & Vulva & Fibroleiomioma & 0 \\
\hline 12 & 14 & Poodle & Vulva & Fibroleiomioma & 1 \\
\hline 13 & 11 & Cocker & Útero & Leiomioma & 0 \\
\hline 14 & 8 & $\mathrm{SRD}^{\mathrm{c}}$ & Útero & Leiomioma & 2 \\
\hline 15 & 11 & SRD & Cérvix & Fibroleiomioma & 0 \\
\hline 16 & 14 & SRD & Útero & Leiomioma & 3 \\
\hline 17 & 9 & Cocker & Vagina & Fibroma & 0 \\
\hline 18 & 12 & Cocker & Vagina & Fibroleiomioma & 0 \\
\hline 19 & 12 & Labrador & Vulva & Leiomioma & 0 \\
\hline 20 & 11 & Dobermann & Útero & Fibroleiomioma & 1 \\
\hline 21 & 12 & SRD & Vulva & Leiomioma & 0 \\
\hline 22 & 2 & Yorkshire & Útero & Fibroleiomioma & 1 \\
\hline 23 & 11 & SRD & Vagina & Fibroleiomioma & 0 \\
\hline 24 & 11 & SRD & Vulva & Leiomiossarcoma & 4 \\
\hline 25 & 8 & Rottweiler & Vagina & Leiomioma & 0 \\
\hline 26 & 12 & Poodle & Vulva & Leiomioma & 1 \\
\hline 27 & 13 & Cocker & Vagina & Fibroleiomioma & 0 \\
\hline 28 & 10 & SRD & Útero & Leiomioma & 0 \\
\hline 29 & 15 & SRD & Vagina & Fibroleiomioma & 0 \\
\hline 30 & NI & SRD & Vulva & Leiomioma & 1 \\
\hline 31 & 13 & Poodle & Útero & Fibroleiomioma & 0 \\
\hline 32 & 12 & SRD & Vulva & Leiomioma & 1 \\
\hline 33 & 13 & Dobermann & Útero & Leiomioma & 0 \\
\hline 34 & 14 & Fila Brasileiro & Vagina & Leiomoioma & 1 \\
\hline 35 & 9 & SRD & Vagina & Leiomioma & 0 \\
\hline 36 & 15 & SRD & Útero & Leiomioma & 2 \\
\hline 37 & 12 & SRD & Vagina & Fibroleiomioma & 1 \\
\hline 38 & NI & SRD & Vulva & Leiomioma & 0 \\
\hline 39 & 10 & SRD & Cérvix & Fibroleiomioma & 0 \\
\hline 40 & NI & Pastor Alemão & Vagina & Fibroleiomioma & 1 \\
\hline 41 & 7 & Schnauzer & Vagina & Leiomioma & 0 \\
\hline 42 & 9 & SRD & Útero & Leiomiossarcoma & 4 \\
\hline 43 & 10 & Cocker & Vagina & Fibroma & 0 \\
\hline
\end{tabular}

a Média da contagem das figuras de mitose em dez campos de grande aumento (objetiva $40 \mathrm{x}$ ), ${ }^{\mathrm{b}} \mathrm{NI}=$ dado não informado, ${ }^{\mathrm{c}} \mathrm{SRD}=$ sem raça definida. sentaram disposição celular em feixes com diferentes direções. Em 33,3\% (6/18) dos fibroleiomiomas e em todos os fibromas as células também formavam ninhos e, em $50 \%$ (1/2) dos leiomiossarcomas, observou-se arranjo sólido.

Quanto à morfologia celular, todos os leiomiomas, os fibroleiomiomas, os fibromas e os leiomiossarcomas apresentaram células com citoplasma eosinofílico de limites indistintos, núcleo alongado a ovoide, cromatina dispersa, exceto em um caso de fibroleiomioma, no qual era condensada. Visualizaram-se 1-2 nucléolos/célula em $60 \%$ $(12 / 20)$ dos casos de leiomioma; em 66,7\% (12/18) dos fi-

Quadro 2. Resultado da coloração de tricrômico de Masson e da imuno-histoquímica para vimentina e desmina dos tumores mesenquimais da genitália de cadelas

\begin{tabular}{|c|c|c|c|c|c|c|}
\hline \multirow[t]{3}{*}{ Caso } & \multirow[t]{3}{*}{ Diagnóstico } & \multirow{3}{*}{$\begin{array}{c}\frac{\text { Histoquímica }}{\text { TM }^{\mathrm{a}}} \\
\text { Distribui- } \\
{\text { ção } \mathrm{TC}^{\mathrm{b}}}\end{array}$} & \multicolumn{4}{|c|}{ Imuno-histoquímica } \\
\hline & & & \multicolumn{2}{|c|}{ Vimentina } & \multicolumn{2}{|c|}{ Desmina } \\
\hline & & & $\begin{array}{l}\text { Distri- } \\
\text { buição }\end{array}$ & $\begin{array}{l}\text { Inten- } \\
\text { sidade }\end{array}$ & $\begin{array}{l}\text { Distri- } \\
\text { buição }\end{array}$ & $\begin{array}{l}\text { Inten- } \\
\text { sidade }\end{array}$ \\
\hline 1 & Fibroleiomioma & $>50 \%$ & $>50 \%$ & ++ & $<50 \%$ & +++ \\
\hline 2 & Fibroleiomioma & $>50 \%$ & - & - & - & - \\
\hline 3 & Leiomioma & $<50 \%$ & $>50 \%$ & + & $>50 \%$ & +++ \\
\hline 4 & Leiomioma & $<50 \%$ & $>50 \%$ & +++ & $<50 \%$ & +++ \\
\hline 5 & Fibroma & $100 \%$ & $>50 \%$ & ++ & - & - \\
\hline 6 & Leiomioma & $<50 \%$ & $>50 \%$ & +++ & $>50 \%$ & +++ \\
\hline 7 & Fibroleiomioma & $>50 \%$ & $>50 \%$ & ++ & $\mathrm{NR}^{\mathrm{c}}$ & NR \\
\hline 8 & Fibroleiomioma & $>50 \%$ & $>50 \%$ & ++ & $<50 \%$ & +++ \\
\hline 9 & Leiomioma & $<50 \%$ & $>50 \%$ & +++ & $<50 \%$ & + \\
\hline 10 & Fibroleiomioma & $>50 \%$ & $>50 \%$ & +++ & $>50 \%$ & ++ \\
\hline 11 & Fibroleiomioma & $>50 \%$ & $>50 \%$ & + & $<50 \%$ & +++ \\
\hline 12 & Fibroleiomioma & $>50 \%$ & $>50 \%$ & ++ & $>50 \%$ & ++ \\
\hline 13 & Leiomioma & $<50 \%$ & $>50 \%$ & ++ & $>50 \%$ & +++ \\
\hline 14 & Leiomioma & $<50 \%$ & $>50 \%$ & +++ & $>50 \%$ & ++ \\
\hline 15 & Fibroleiomioma & $>50 \%$ & $>50 \%$ & ++ & $>50 \%$ & +++ \\
\hline 16 & Leiomioma & $<50 \%$ & $>50 \%$ & ++ & $>50 \%$ & +++ \\
\hline 17 & Fibroma & $100 \%$ & $>50 \%$ & +++ & - & - \\
\hline 18 & Fibroleiomioma & $>50 \%$ & $>50 \%$ & +++ & - & - \\
\hline 19 & Leiomioma & $<50 \%$ & $>50 \%$ & ++ & $>50 \%$ & ++ \\
\hline 20 & Fibroleiomioma & $>50 \%$ & $>50 \%$ & ++ & $<50 \%$ & +++ \\
\hline 21 & Leiomioma & $<50 \%$ & $>50 \%$ & + & $<50 \%$ & +++ \\
\hline 22 & Fibroleiomioma & $>50 \%$ & $>50 \%$ & +++ & $<50 \%$ & ++ \\
\hline 23 & Fibroleiomioma & $>50 \%$ & $>50 \%$ & ++ & NR & NR \\
\hline 24 & Leiomiossarcoma & $<50 \%$ & $>50 \%$ & +++ & - & - \\
\hline 25 & Leiomioma & $<50 \%$ & $>50 \%$ & +++ & $>50 \%$ & +++ \\
\hline 26 & Leiomioma & $<50 \%$ & $>50 \%$ & ++ & $>50 \%$ & +++ \\
\hline 27 & Fibroleiomioma & $>50 \%$ & $>50 \%$ & +++ & $<50 \%$ & + \\
\hline 28 & Leiomioma & $<50 \%$ & $>50 \%$ & +++ & $>50 \%$ & +++ \\
\hline 29 & Fibroleiomioma & $>50 \%$ & $>50 \%$ & + & $>50 \%$ & +++ \\
\hline 30 & Leiomioma & $<50 \%$ & $>50 \%$ & ++ & $>50 \%$ & +++ \\
\hline 31 & Fibroleiomioma & $>50 \%$ & $>50 \%$ & +++ & $<50 \%$ & +++ \\
\hline 32 & Leiomioma & $<50 \%$ & $>50 \%$ & ++ & $<50 \%$ & +++ \\
\hline 33 & Leiomioma & $<50 \%$ & $>50 \%$ & ++ & $>50 \%$ & +++ \\
\hline 34 & Leiomioma & $<50 \%$ & $>50 \%$ & ++ & $>50 \%$ & +++ \\
\hline 35 & Leiomioma & $<50 \%$ & $>50 \%$ & + & $>50 \%$ & +++ \\
\hline 36 & Leiomioma & $<50 \%$ & $>50 \%$ & ++ & $>50 \%$ & +++ \\
\hline 37 & Fibroleiomioma & $>50 \%$ & $>50 \%$ & +++ & $<50 \%$ & + \\
\hline 38 & Leiomioma & $<50 \%$ & $>50 \%$ & ++ & $<50 \%$ & +++ \\
\hline 39 & Fibroleiomioma & $>50 \%$ & $>50 \%$ & ++ & $<50 \%$ & ++ \\
\hline 40 & Fibroleiomioma & $>50 \%$ & $>50 \%$ & +++ & $>50 \%$ & +++ \\
\hline 41 & Leiomioma & $<50 \%$ & $>50 \%$ & ++ & $>50 \%$ & +++ \\
\hline 42 & Leiomiossarcoma & $<50 \%$ & - & - & $>50 \%$ & ++ \\
\hline 43 & Fibroma & $100 \%$ & $>50 \%$ & ++ & - & - \\
\hline
\end{tabular}

a $\mathrm{TM}=$ coloração de tricrômico de Masson; ${ }^{\mathrm{b}} \mathrm{TC}=$ Tecido conjuntivo fibroso; ${ }^{\mathrm{c}} \mathrm{NR}=$ técnica não realizada. Intensidade de marcação: - negativo, + discreta, ++ moderada, +++ acentuada; $>50 \%=$ mais de $50 \%$ das células marcadas, $<50 \%=$ menos de $50 \%$ das células marcadas, $100 \%=100 \%$ de células marcadas. 
broleiomiomas; $33,3 \%(1 / 3)$ dos fibromas e em $50 \%(1 / 2)$ dos leiomiossarcomas; $1-3$ nucléolos em $25 \%(5 / 20)$ dos leiomiomas, $16,7 \%$ (3/18) dos fibroleiomiomas, $66,7 \%$ (2/3) dos fibromas e em $50 \%$ (1/2) dos leiomiossarcomas; e de 1-6 nucléolos em 5,6\% (1/18) dos fibroleiomiomas. Em 15\% (3/20) dos leiomiomas e em 11,1\% (2/18) dos fibroleiomiomas não havia evidenciação de nucléolos.

0 pleomorfismo foi considerado baixo em todos os casos, com exceção dos leiomiossarcomas, em que havia anisocitose e anisocariose moderadas a acentuadas, sem células bizarras ou mitoses atípicas. Na avaliação das figuras de mitose, cujos dados por cão são apresentados no Quadro 1 , os casos de leiomiossarcoma apresentaram o índice mitótico superior a 3, enquanto que, nos demais neoplasmas, foi inferior.

Observou-se ulceração localmente extensa da mucosa da genitália em 15\% (3/20) dos leiomiomas, 22,2\% (4/18) dos fibroleiomiomas e em 33,3\% (1/3) dos fibromas. Havia necrose multifocal em $10 \%(2 / 20)$ dos leiomiomas e em $50 \%(1 / 2)$ dos leiomiossarcomas e infiltrado inflamatório linfoplasmocitário ou de neutrófilos em meio às células ne- oplásicas em 10\% (2/20) dos leiomiomas, 5,56\% (1/18) dos fibromas e em $50 \%(1 / 2)$ dos leiomiossarcomas.

\section{Caracterização histoquímica e imuno-histoquímica}

0 perfil histoquímico e de IHQ de cada caso encontra-se no Quadro 2. Nos três casos de fibroma todas as células neoplásicas foram coradas em azul, caracterizando assim a composição por tecido conjuntivo (Fig.1A) e houve imunopositividade citoplasmática para o anticorpo anti-vimentina em mais de $50 \%$ das células (Fig.1B) e ausência de marcação para desmina.

Nos leiomiomas, todos os casos apresentaram menos de $50 \%$ das células marcadas em azul pela coloração de TM (Fig.2A) e todos foram positivos para a vimentina em mais de $50 \%$ das células. Quanto à desmina, todos os casos também foram positivos, sendo que $75 \%$ (15/20) desses apresentaram marcação em mais de $50 \%$ das células (Fig.2B) e $25 \%$ (5/20) em menos de $50 \%$.

Nos dois casos de leiomiossarcoma observou-se menos de $50 \%$ de tecido conjuntivo em meio às células neoplásicas pela coloração de TM. Quanto à IHQ, em um caso houve
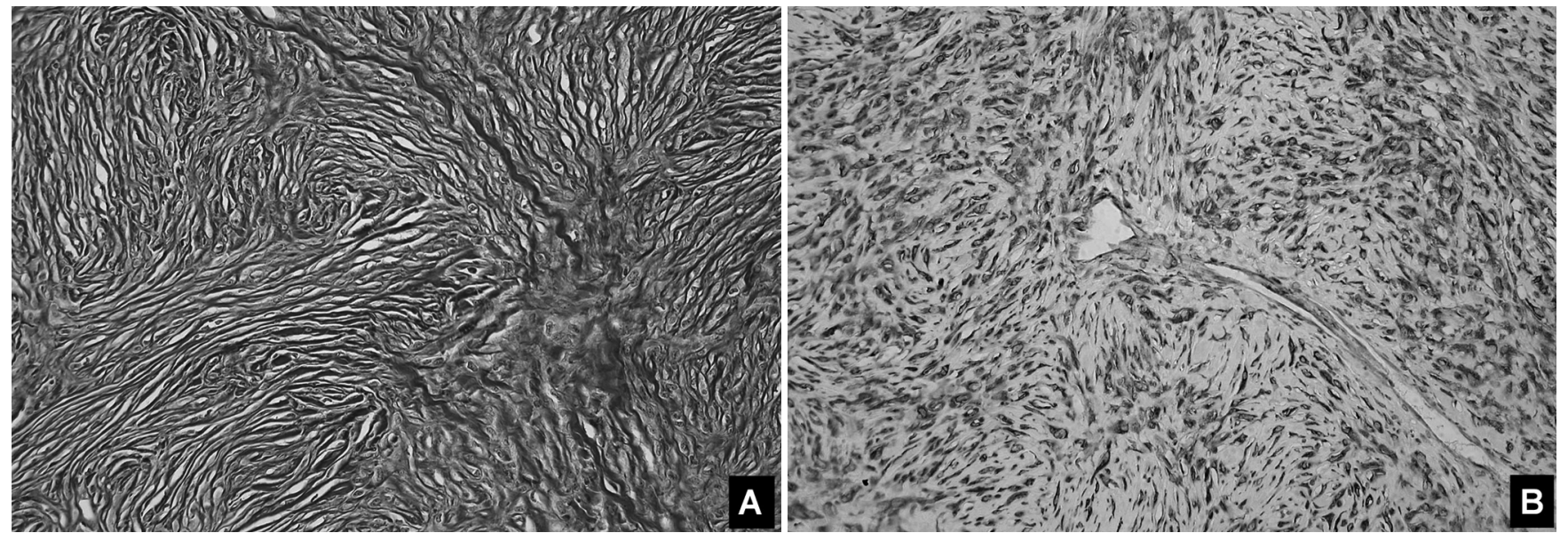

Fig.1. Fibroma em genitália de cadela (Caso 17). (A) Citoplasma de células neoplásicas corado em azul, caracterizando tecido conjuntivo. Tricrômico de Masson, obj.20x. (B) Imunomarcação para vimentina difusa no citoplasma das células tumorais. Método de estreptavidina-biotina-peroxidase contracorado com hematoxilina de Harris, obj. 40x.
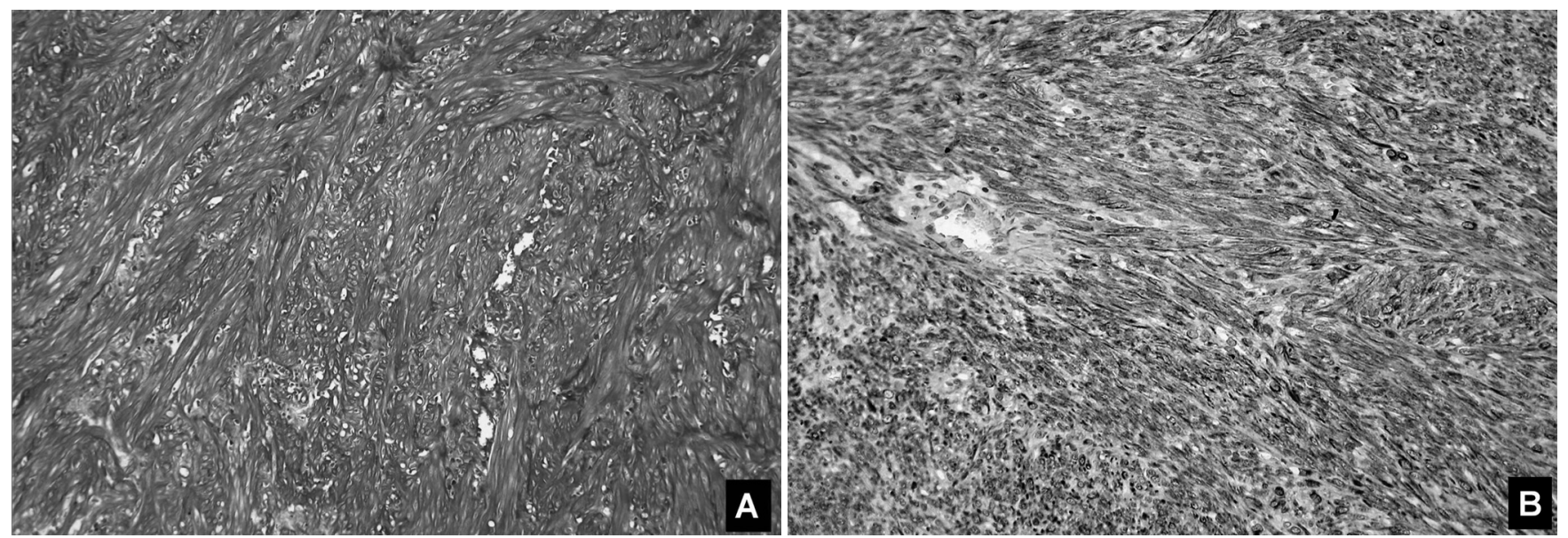

Fig.2. Leiomioma em genitália de cadela. (A) Mais de 50\% das células neoplásicas com citoplasma corado em vermelho (músculo) e o restante em azul (colágeno) (Caso 34). Tricrômico de Masson, obj.20x. (B) Imunomarcação para desmina no citoplasma de mais de $50 \%$ das células tumorais (Caso 16). Método de estreptavidina-biotina-peroxidase contracorado com hematoxilina de Harris, obj. $40 \mathrm{x}$. 


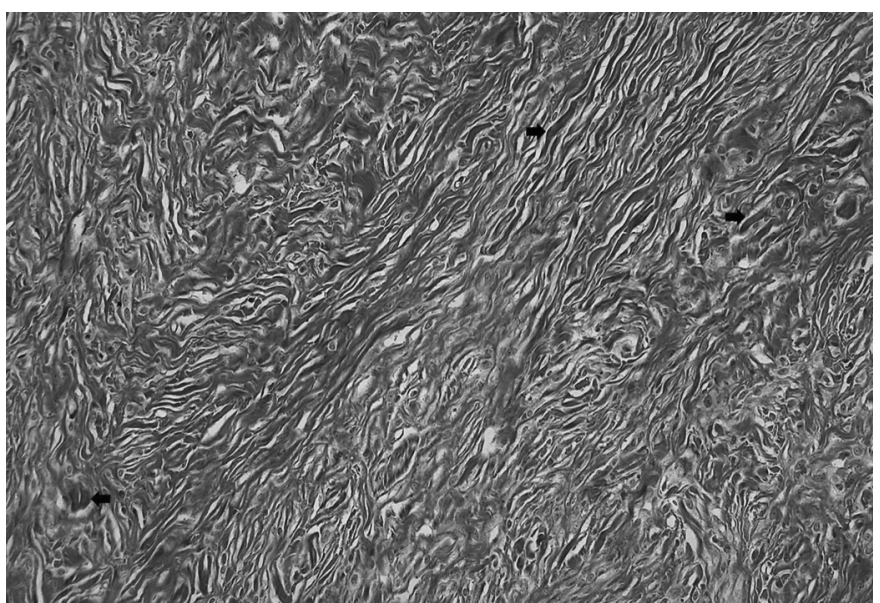

Fig.3. Fibroleiomioma em genitália de cadela (Caso 27). Mais de $50 \%$ das células neoplásicas com citoplasma corado em azul (colágeno) e raras células com citoplasma corado em vermelho (músculo) (setas). Tricrômico de Masson, obj.20x.

imunomarcação para vimentina em mais de $50 \%$ das células e ausência de marcação para desmina e, no outro, imunomarcação para desmina em mais de $50 \%$ das células e ausente para a vimentina.

Em todos os fibroleiomiomas observaram-se mais de $50 \%$ das células neoplásicas marcadas em azul pela coloração de TM (Fig.3). Foi observada marcação positiva para os dois anticorpos utilizados em 77,8\% (14/18) dos casos. Quanto à vimentina, 94,4\% (17/18) dos casos tiveram marcação em mais de $50 \%$ das células. Desses casos positivos para vimentina, em 52,9\% (9/17) houve marcação para a desmina em menos de 50\% das células; em 29,4\% (5/17) em mais de 50\% das células; em 11,8\% (2/17) essa reação não foi realizada por falta de amostra tecidual e, em 5,9\% (1/17), não houve marcação. Em um caso não se observou marcação para vimentina nem para desmina.

\section{DISCUSSÃO}

O leiomioma é considerado o neoplasma mesenquimal mais frequente na genitália tubular de cadelas, seguido pelo fibroma, o fibroleiomioma e o leiomiossarcoma (Kennedy et al. 1998, MacLachlan \& Kennedy 2002). No presente estudo, o leiomioma e o fibroleiomioma apresentaram prevalências semelhantes, $46,5 \%$ e $41,9 \%$, respectivamente. A maioria das descrições desses tumores é realizada com base na coloração de HE apenas. Assim sendo, muitos patologistas podem considerar casos de fibroleiomioma como leiomioma. 0 fibroma e o leiomiossarcoma tiveram prevalência baixa nesse estudo.

No Brasil não há relato de estudos retrospectivos desses neoplasmas em cadelas. Nos Estados Unidos, em um estudo de 90 casos de neoplasmas de útero, vagina e vulva em cadelas, 70 deles eram leiomioma, quatro leiomiossarcoma e o restante era de origem mesenquimal não fusiforme, ou epitelial (Brodey \& Roszel 1967). Em outro estudo, de 99 casos de tumores de vulva e vagina, os mais prevalentes foram o fibroma, o leiomioma e o leiomiossarcoma com 27, 26 e 10 casos, respectivamente (Thacher \& Bradley 1983). E, de um estudo retrospectivo de 117 tumores do aparelho reprodutor de cadelas no México, dos neoplasmas mesenquimais de células fusiformes foram relatados apenas três casos de leiomioma (Cruz et al. 1997).

Neste estudo, os tumores estavam localizados mais frequentemente na vagina $(44,2 \%)$ seguida pelo útero $(27,9 \%)$, vulva $(23,3 \%)$ e cérvix $(4,6 \%)$. Os estudos retrospectivos realizados anteriormente apontam que a vagina e a vulva são locais mais comumente afetados que o útero (Brodey \& Roszel 1967, Thacher \& Bradley 1983, Cruz et al. 1997, Cooper \& Valentine 2002). Esses neoplasmas são hormônio-dependentes e, como observado no presente trabalho, ocorrem em fêmeas não-castradas. Há apenas um relato de leiomioma uterino em uma cadela de 16 anos, parcialmente castrada, a qual apresentava resquício de ovário e útero (Sontas et al. 2008).

As células neoplásicas dos tumores de músculo liso podem apresentar receptores para os hormônios esteroidais. Em um estudo com 32 tumores genitais de cadela (leiomioma, fibroleiomioma e leiomiossarcoma), 56,3\% apresentaram expressão para receptor de estrógeno tipo alfa e 84,4\% para receptor de progesterona (Millán et al. 2007). Essa característica pode possibilitar a realização de terapia hormonal nas cadelas acometidas.

Essas alterações hormonais podem influenciar o aparecimento de problemas reprodutivos que causam infertilidade ou até mesmo a morte do animal. No presente trabalho foram observados hiperplasia endometrial cística, piometra e cistos ovarianos associados aos neoplasmas. Em um estudo foram relatados piometra, pseudociese, corrimento vulvar e tumores mamários (Thacher \& Bradley 1983). Em outro levantamento foram observados hiperplasia endometrial cística, piometra, cistos ovarianos, neoplasias de mama, ovário e pele (Brodey \& Roszel 1967).

Neste levantamento, a maioria das cadelas era SRD. Dos cães com raça definida, os mais afetados foram Cocker, Poodle e Pastor Alemão. Não existem estudos que apontem predisposição racial para o aparecimento de neoplasmas no trato genital de cadelas, porém, em alguns estudos, a raça Boxer tem apresentado uma maior prevalência (Brodey \& Roszel 1967, Cooper \& Valentine 2002).

Verificou-se que a coloração de TM é muito útil na diferenciação entre tecido muscular e colagenoso. É de baixo custo e pode ser empregada na rotina de diagnóstico de patologia veterinária para diferenciar leiomioma, fibroleiomioma e fibroma, uma vez que é difícil caracterizá-los apenas pela HE. Poucos trabalhos utilizaram TM para diferenciar e caracterizar esses neoplasmas (Munday \& Stedman 2002, Manarolla et al. 2011) e, nesses trabalhos, também se constatou que a coloração de TM é tão útil nesse diagnóstico quanto a IHQ. A IHQ com marcadores de músculo liso como a actina, a desmina e a calponina é amplamente utilizada para o diagnóstico desses neoplasmas (Cooper \& Valentine 2002, Millán et al. 2007, Manarolla et al. 2011). Nesse trabalho foram utilizadas a vimentina e a desmina. Em um caso de leiomiossarcoma observou-se marcação apenas para vimentina e, no outro, apenas para a desmina. Neoplasmas malignos, ou até mesmo benignos, podem apresentar células tumorais que perdem os receptores para esses anticorpos. Em um caso de lipoleiomioma vulvar em 
cadela é relatada ausência de imunomarcação para vimentina e positiva apenas para desmina e actina (Radi 2005).

Nem todos os fibroleiomiomas apresentaram marcação para a vimentina e a desmina. No caso em que não houve marcação para ambos os anticorpos pode ter ocorrido falha na fixação ou no processamento do tecido, que interferiu na reação de IHQ. Nos casos negativos apenas para um marcador pode ter ocorrido falta de afinidade do anticorpo primário ao tecido, ou perda dos receptores celulares. Em seis casos de fibroleiomioma de baleia, apenas três apresentaram marcação para desmina e um para vimentina (Mikaelian et al. 2000). Em outro estudo, de 22 casos de leiomioma e leiomiossarcoma de cães, apenas 14 eram positivos para desmina (Andreasen \& Mahaffey 1987).

Os resultados obtidos neste estudo retrospectivo possibilitam concluir que as cadelas acometidas por neoplasmas mesenquimais da genitália eram velhas e as mais acometidas eram SRD. Os tumores mais frequentes foram o leiomioma e o fibroleiomioma e a vagina foi a região mais acometida. Devido à dificuldade de diferenciar colágeno de músculo liso pela coloração de HE, ressalta-se a importância da realização da coloração de TM e do painel imuno-histoquímico, sobretudo da desmina.

Agradecimentos.- À Coordenação de Aperfeiçoamento de Pessoal e Nível Superior (CAPES) e Conselho Nacional de Desenvolvimento Científico e Tecnológico (CNPQ) pelo apoio financeiro.

\section{REFERÊNCIAS}

Andreasen C.B. \& Mahaffey E.A. 1987. Immunohistochemical demonstration of desmin in canine smooth muscle tumors. Vet. Pathol. 24:211215.

Brodey R.S. \& Roszel J.F. 1967. Neoplasms of the canine uterus, vagina, and vulva: A clinicopathologic survey of 90 cases. J. Am. Vet. Med. Assoc. 151:1294-1306.

Cooper B.J. \& Valentine B.A. 2002. Tumor of muscle, p.319-364. In: Meuten D.J. (Ed.), Tumors in Domestic Animals. $4^{\text {th }}$ ed. Iowa State Press, Ames.

Cruz G.G., Buitrago C.A.S., Hernández M.E.V. \& Buen N. 1997. Neoplasias em aparato reproductor em perras: estudio retrospectivo de 6 años. Vet. Méx. 1:31-34.

Kennedy P.C., Cullen J.M., Edwards J.F., Goldschmidt M.H., Larsen S. \& Munson L. 1998. Histological Classification of Tumors of the Genital System of Domestic Animals. $2^{\text {nd }}$ ed. Armed Forces Institute of Pathology, Washington. 78p.

MacLachlan N.J. \& Kennedy P.C. 2002. Tumor of the genital systems, p.547573. In: Meuten D.J. (Ed.), Tumors in Domestic Animals. $4^{\text {th }}$ ed. Iowa State Press, Ames.

Manarolla G., Caseiro S., Sironi G. \& Rampin T. 2011. Morphological and immunohistochemical observations on leiomyoma of the ventral ligament of oviduct of the hen. J. Comp. Pathol. 144:180-186.

Mikaelian I., Labelle P., Doré M. \& Martineau D. 2000. Fibroleiomyomas of the tubular genitalia in female beluga whales. J. Vet. Diagn. Invest. 12:371-374

Millán Y., Gordon A., Espinosa de Los Monteros A., Reymundo C. \& Martín de Las Mulas J. 2007. Steroid receptors in canine and human female genital tract tumors with smooth muscle differentiation. J. Comp. Pathol. 136:197-201.

Munday J.S. \& Stedman N.L. 2002. Uterine leiomyomas in two Vietnamese Pot-bellied pigs (Sus scrofa). Vet. Pathol. 39:580-583.

Radi Z.A. 2005. Vulvar lipoleiomyoma in a dog. J. Vet. Diagn. Invest. 17:8990.

Schlafer D.H. \& Miller R.B. 2007. Female genital system, p.429-564. In: Maxie M.G. (Ed.), Jubb, Kennedy, and Palmer's Pathology of Domestic Animals. $5^{\text {th }}$ ed. Elsevier, Philadelphia.

Sontas B.H., Özyogurtcu H., Turna Ö., Arun S. \& Ekici H. 2008. Uterine leiomyoma in a spayed poodle bitch: a case report. Reprod. Dom. Anim. 45:550-554.

Thacher C. \& Bradley R.L. 1983. Vulvar and vaginal tumors in the dog: A retrospective study. J. Am. Vet. Med. Assoc. 183:690-692. 